\title{
POLICY ANALYSIS OF LEPROSY CONTROL: A SYSTEMATIC REVIEW
}

\author{
Dian Ayu Pertiwi'), Dumilah Ayuningtyas²) \\ 1)Public Health Masters Program, Faculty of Public Health, \\ Universitas Indonesia \\ 2)Department of Health Policy and Administration, \\ Faculty of Public Health, Universitas Indonesia
}

\begin{abstract}
Background: Leprosy is a slowly progressive and chronic infectious disease caused by Mycobacterium leprosy. In many parts of the world, this is a very serious and humiliating disease. Early diagnosis and treatment are the most important strategies to control it. This study aimed to describe and analyze specific policies and strategies for people with leprosy.

Subject and Method: A systematic review was conducted by searching articles in 2 electronic databases, namely PubMed and Mendeley. The articles were collected based on PRISMA flow diagram.

Results: From the ten articles that were collected, it was reported that the leprosy control policy could be carried out in several ways: (1) including government policies related to socio-economy, especially for the poor (2) eliminating the negative stigma about leprosy sufferers, and (3) the system of giving drug therapy through Multi-Drug Therapy. Of the seven journals that are a synthesis review, other things need to be considered related to leprosy control, including gender and leprosy diagnosis must be made as soon as possible before lepers suffer from a worse illness. Conclusion: socio-economic policies, eliminating stigma, providing drug therapy with MDT can reduce leprosy in a region.
\end{abstract}

Keywords: leprosy control, systematic review

\section{Correpondence:}

Dian Ayu Pertiwi. Public Health Masters Program, Faculty of Public Health, Universitas Indonesia, Depok, West Java. Email: madd209@yahoo.com. Mobile: 082124901758 